eISSN 2444-7986

DOI: https://doi.org/10.14201/orl.18665

Carta al director

\title{
¡SEIS MANERAS DE SACARLE PROVECHO A SU ORCID ID!
}

\author{
Six Ways to Make Your ORCID iD Work for You!
}

\author{
Alice MEADOWS ${ }^{1}$; Gabriela MEJÍAS ${ }^{2}$ \\ ${ }^{1}$ ORCID. Director, Community Engagement and Support. Brookline, United States. ${ }^{2}$ ORCID: Berlin, Alemania \\ Correspondencia:g.mejias@orcid.org
}

Traducción del original «Six Ways to Make Your ORCID iD Work for You!» publicado en https://orcid.org/blog/2017/08/10/six-ways-make-your-orcid-id-work-you el 10 de agosto de 2017

Fecha de publicación: 19 de junio de 2018

Fecha de publicación del fascículo: 1 de diciembre de 2018

Conflicto de intereses: Los autores declaran no tener conflictos de intereses

Imágenes: Los autores declaran haber obtenido las imágenes con el permiso de los pacientes

Política de derechos y autoarchivo: se permite el autoarchivo de la versión post-print (SHERPA/RoMEO)

Licencia CC BY-NC-ND. Licencia Creative Commons Atribución-NoComercial-SinDerivar 4.0 Internacional

Universidad de Salamanca. Su comercialización está sujeta al permiso del editor

¡Felicidades, usted ha registrado su ORCID iD! [1]. El siguiente paso es usar su iD para construir su registro ORCID. Sabemos que lo último que desea es tener que pasar más tiempo actualizando otro sistema, entonces ¿por qué no permitir que las organizaciones y plataformas con las que ya interactúa hagan la mayor parte del trabajo por usted? No sólo le ahorrará tiempo, sino que también reducirá el riesgo de errores y le ayudará a garantizar conexiones confiables entre usted y sus contribuciones de investigación y afiliaciones.

Después de todo, ¿quién mejor que su institución para confirmar dónde trabaja? ¿O una revista para validar los artículos que usted ha escrito?

Recomendamos seguir estos seis sencillos pasos para crear un registro autorizado de ORCID, jtan sólo levantando un dedo (digital)!:

1. Afiliación verificada por su institución. Use su ORCID iD cada vez que se le solicite hacerlo en un sistema en el que confía: el sistema de administración de información de su institución, un sistema de envío de manuscritos o solicitud de financiamiento, entre otros. Las mejores integraciones de
ORCID le solicitarán que inicie sesión en su cuenta de ORCID para verificar su iD. Al mismo tiempo, muchos de ellos le pedirán autorización para acceder a su registro.

¡Diga que sí! Dichos sistemas luego podrán agregar información a su registro ORCID y mantenerla actualizada. Esto significa que, por ejemplo, su institución puede agregar información de afiliación, incluir la fecha de inicio de la misma, y editarla si cambia de departamentos o abandona la organización. Su institución aparecerá como la fuente de esa información. Puede optar por revocar el acceso a través de la configuración de su cuenta ORCID en cualquier momento si lo necesita [2].

2. Actualizaciones automáticas en su registro a medida que publica. Autorice a Crossref [3] y DataCite [4], los principales proveedores de DOI para publicaciones de investigación, a actualizar automáticamente su registro cada vez que publique un artículo o conjunto de datos en una revista. 
Crossref solicitará su permiso una vez que su trabajo haya sido aceptado: busque un correo electrónico de ellos y, cuando se le solicite, inicie sesión en su cuenta ORCID y autorícelos a actualizar su registro. Puede activar la función de actualización automática de DataCite usted mismo, independientemente del proceso de publicación. Simplemente configure un perfil de DataCite [5] y habilite la funcionalidad de actualización automática de ORCID. Después de eso, su registro ORCID se actualizará automáticamente cada vez que se publique uno de sus trabajos. Crossref o DataCite aparecerán como la fuente de la información. A menudo, su registro se actualizará antes de que el artículo siquiera se publique.

3. Conéctese a sus trabajos existentes. Use las herramientas de ORCID para «Buscar y Enlazar». Hasta el momento, once de nuestras organizaciones miembro han creado estas herramientas, que le permiten conectar sus trabajos de manera rápida y fácil a su registro. Puede importar información de algunas de las bases de datos más grandes, como Crossref Metadata Search, ResearcherID y ScopusID; bases de datos de disciplinas específicas como Europe PubMed Central y MLA International Bibliography; y bases de datos específicas a países e idiomas como Airiti, KoreaMed y Redalyc. Seleccione la opción «Buscar y Enlazar» debajo de «Agregar obras» en la sección "Obras» de su registro ORCID, elija la base de datos con la que desea conectarse y conceda permiso para que acceda y actualice su registro ORCID. Se le presentará una lista de publicaciones que coinciden con la información en su registro, y usted simplemente selecciona las que son suyas. Aparecerán inmediatamente en su registro ORCID, con la base de datos relevante indicada como la fuente.

4. Conéctese a sus subvenciones existentes. Use la herramienta «Buscar y Enlazar» de UberResearch. Funciona de manera muy similar a las herramientas de búsqueda y enlace para obras, lo que le permite conectar de manera rápida y fácil sus becas y premios a su registro ORCID. Haga clic en la opción «Buscar y Enlazar» en la sección «Financiamiento» de su registro, seleccione UberWizard, autorice la conexión y seleccione sus subvenciones de la misma manera que lo hace con sus obras. La fuente de la información será UberResearch.

5. Conecte sus perfiles existentes a su registro ORCID. ¿Ya tiene un perfil de ResearcherID o ScopusID? ¿Qué hay de Kudos, Loop, Mendeley o Publons? Estos y otros sistemas de investigadores le han permitido conectar información a su registro ORCID. Cada uno funciona de manera ligeramente diferente, pero en todos los casos se le ofrecerá la opción de vincular su iD a su perfil y se le pedirá que otorgue permiso para actualizar su registro ORCID. ¡No es necesario volver a introducir la misma información! Puede encontrar que los mismos trabajos se agregan a su registro ORCID varias veces; si es así, los agruparemos automáticamente por identificador de trabajo. Si no hay un identificador, puede optar por agruparlos manualmente si lo desea.

6. Conecte su ORCID iD con sus credenciales institucionales de inicio de sesión. Ahorre tiempo y disminuya el riesgo de perder inadvertidamente el acceso a su cuenta ORCID vinculando su iD con su inicio de sesión institucional. También puede conectarse a sus cuentas de Facebook o Google. Esto significa una contraseña menos para recordar y también garantiza que tiene más de una forma de acceder a su cuenta ORCID. Obtenga más información aquí [6].

Cada semana se conectan más sistemas a ORCID. Busque el icono verde del ORCID iD en los sistemas de investigación que utiliza.

\section{ENLACES RELACIONADOS}

1. https://orcid.org/register

2. https://support.orcid.org/knowledgebase/ar ticles/148603-account-settings

3. https://www.crossref.org/

4. https://www.datacite.org/

5. https://profiles.datacite.org/

6. https://support.orcid.org/knowledgeba se/articles/892920-different-ways-tosign-into-orcid 